\title{
Why we should care about poverty and inequality: exploring the grounds for a pluralist
}

\section{approach}

Policy debates surrounding poverty and inequality often focus on practical solutions and seldom explore the normative underpinning that would justify our concerns with these phenomena. Why should we care about poverty, or about inequality? From a philosophical standpoint, can we separate the two, such that it is possible to be deeply concerned about poverty but unconcerned about inequalities? Do our reasons for caring about one contrast with our reasons for caring about the other? While there is a growing empirical literature exploring the mechanisms connecting the two, the philosophical literature has seldom focused on their relationship. Firstly, this paper provides a clear map of the philosophical debate, clarifying the normative assumptions that underlie positions conceptually prioritizing inequality and poverty respectively. Secondly, the paper suggests "a pluralist approach", that stresses the overlap of our normative concerns with poverty and inequality and highlights parallel problems that restrictive interpretations of these concepts face, pointing to the importance of considering broader phenomena and processes (such as deprivation and exclusion) that illuminate the relationship between the two.

The social policy literature has long explored the empirical relationship between poverty and inequality. Since the 1950s, a dominant position in economic and political debates advocated for a 'rising tide hypothesis' (Stiglitz, 2015). This tradition assumed a trade-off between equality and growth and connected inequalities to positive incentives to work, to the acquisition of human capital, investment, and risk-taking that would boost growth. Economic growth would bring increasing opportunities and higher living standards to all sections of society. In this sense, regressive economic policies - policies that favour the richer classes - would end up benefiting everyone, and resources given to the rich would inevitably 'trickle down' to the rest. In this respect, inequality would reduce poverty, due to its relationship to economic growth. However, recent studies have put these relationships into question: for instance, recent work from the International Monetary Fund (IMF, 2014) has come to the conclusion that inequality negatively affects growth and its sustainability. This has revived interest in the empirical relations between inequality and poverty. 
At the same time, policy debates surrounding poverty and inequality often focus on practical solutions and seldom explore the normative underpinning that would justify our concerns with these phenomena. Why should we care about poverty, or about inequality? From a philosophical standpoint, can we separate the two, such that it is possible to be deeply concerned about poverty but unconcerned about inequalities at the top of society? Do our reasons for caring about one contrast with our reasons for caring about the other? Identifying these different normative reasons can lead us to claim that one issue should have priority over the other and can justify a particular policy focus. In order for the philosophical literature to speak to current debates in social policy, it is essential to focus on the conceptual relations between poverty and inequality and explore the extent to which our normative concerns are compatible and can, in fact, overlap.

The aim of this paper is to push this discussion forward and, in doing so, it has two main objectives: on the one hand, it provides a clear map of the philosophical debate, clarifying the normative assumptions that underlie positions conceptually prioritizing inequality $(\S 1)$ and poverty $(\S 2)$. What emerges from the philosophical literature is a picture that doesn't explicitly tackle the relationship between poverty and inequality. Following Rawls's influential work, a vast literature has focused on inequality and debated fundamental principles of justice. Frankfurt's critique of egalitarianism has supported a shift of focus on poverty through the development of sufficiency views. At the same time, humanitarian views (Singer, 1972; Campbell, 2007), as well as current debates on subsistence rights and global poverty (Pogge, 2007) have developed in relative isolation from the discourse around inequality.

A second objective of this paper, then, is to present what I will deem a "pluralist approach", that stresses how our normative concerns with poverty and inequality can be compatible ( $\$ 3)$. This approach highlights parallel problems that restrictive interpretations of the concepts of poverty and inequality face, and points to the importance of considering broader phenomena and processes (such 
as deprivation and exclusion) that illuminate the relationship between the two. A focus on the relationship between poverty and inequality can allow us to identify questions that emerge in relation to both, for example concerning the role of agency, with similar transversal concerns in regards to individual and collective responsibility $(\S 4)$. Finally, I will point to directions through which a pluralist approach can be used in current policy debates and can allow us to distinguish and explain differences between approaches to policy; I will show this in relation to the current debate surrounding conceptions of inclusive growth.

\section{Giving priority to inequality}

Following Rawls's legacy, a key normative concern with distributional inequality can be seen as deriving from the idea that inequality constitutes injustice: Rawls advances a political conception of justice that pertains to the 'basic structure of society' and offers the conditions of fairness for political institutions through two principles (1971, pp. 42-43). These principles, he argues, are the terms of cooperation which free and equal citizens would agree to under fair conditions, and they are expressive of citizens' respect for one another as moral persons. According to Rawls, the consensus reached over the principles of justice does not entail a comprehensive theory of the 'good'. It is because of this that, rather than referring to particular ends, Rawls's theory is explicitly focused on 'social primary goods': the 'all-purpose means' which are valuable, whatever one's individual conception of the good is. These primary goods include liberty, opportunity, the powers and prerogatives of office, the social bases of self-respect, income, and wealth. The first principle affirms for all citizens familiar basic rights and liberties, while the second constrains social and economic inequalities by requiring fair equality of opportunity and affirming the 'difference principle', which regulates the distribution of wealth and income. According to this principle, a just society is one where inequalities of wealth and income work to the greatest benefit of the least-advantaged members of society. 
As a so-called 'ideal theory', Rawls's view attempts to set out the principles of justice that abstract from particular conditions, but also provide the model to which society should aspire. At the same time, the ideal nature of the theory allows us to understand why poverty does not figure prominently in this discussion. According to Rawls poverty is one of the "great evils of human history", but it is thought to fundamentally "follow from political injustice... once the gravest forms of political injustice are eliminated by following just (or at least decent) social policies and establishing just (or at least decent) basic institutions, these great evils will eventually disappear" (Rawls, 1999, pp. 6-7). In this ideal approach, inequality is the primary concern, because it defines the grounds of justice. The difference principle, for example, does not equate the "worst off" and the "poor": while these notions can coherently overlap in practice, Rawls's theory addresses fairness in relation to the former, going beyond confronting poverty. Much of the debate that The Theory of Justice originated preserves this focus on inequality and has developed both in the direction of spelling out the "currency" of justice (Cohen, 1989), the things which people should have equal amounts of in an equal society; but also in the direction of articulating the principles defining which inequalities amount to injustice (Dworkin, 1981a; 1981b; Parfit, 1998). Some of these issues will be directly addressed in the next sections.

Finally, views that see inequality as central to social justice need to be distinguished from instrumental views, according to which our concern with inequality is derivative of other social, economic and political goals. Kate Pickett and Richard Wilkinson's well-known book, The Spirit Level: Why equality is better for everyone shows a series of strong associations between income inequality and adverse social outcomes, making the claim that the associations are causal. Some current research suggests that inequality has negative effects on: social cohesion (Bridstall, 2007); political stability (Stewart, 2013; Salomon, 2011); and democratic participation (Solt, 2008; 2010). In all these cases, there are prudential reasons to avoid generating or exacerbating inequalities because 
these are considered obstacles to the achievement of further goals. In this sense, empirical evidence that disproves such links, or suggests a different relation between inequality and these primary goals, can justify abandoning our concern with inequality in a way that a view conceiving inequality as central to social justice does not. This is not to say that empirical evidence has no place in views that conceive inequalities as basically unjust: empirical evidence can be used to show that particular states of affairs are unjust. In these cases, evidence can thus support the case for taking particular actions, while also explaining the specific mechanisms generating inequalities. Empirical evidence does not, however, ground our normative concern with inequality.

Utilitarianism is an example of a view that presents reasons for caring about inequalities which are instrumental, contingent and incidental. In fact, while utilitarianism holds an egalitarian principle in treating the interests of all equally, it lacks a concept of justice or fairness that isn't derivative of its own guiding principle of maximizing utility. This means that, for utilitarians, the extent of inequality should depend on which distribution maximizes utility. This position remains contingent on the empirical connections between inequality and utility maximization. While this can lead to highly egalitarian conclusions, for example on the basis of arguments for equality based on diminishing marginal utility (Pigou, 1920), it can also justify material inequality in order to avoid negative incentives to work or promote positive incentives rewarding productivity. Because utilitarianism defines what is right only as a function of the good, understood as utility maximization, it allows to justify the inequalities instrumental to this good. ${ }^{1}$

\section{Giving priority to poverty}

Within the debate surrounding the principles of fairness, and potential instrumental role of inequality, we find views that deny that the demands of justice involve comparative principles. Frankfurt has stressed that "what is important from the point of view of morality is not that everyone should have 
the same but that each should have enough. If everyone had enough it would be of no moral consequence whether some had more than others" (1987, pp. 21-2). Frankfurt refutes the argument for equality based on diminishing marginal utility and discusses how the concept of "equal share" is simpler and more accessible than the concept of "having enough" and has thus been - mistakenly, in his view - the focus of attention. A sufficiency view gives normative priority to reaching the central standards of a dignified life: we should care about whether people have good lives, not how their lives compare to others. Setting aside for the moment what "having enough" entails, we can see that it is possible for a sufficiency view such as Frankfurt's to be consistent with Rawls's difference principle, but this is only incidentally and contingently so. Instrumentally, redistribution and policies tackling vertical inequalities might be necessary to reach sufficiency; however, given the choice between achieving the goal of sufficiency through redistribution that diminishes wealth inequalities and reaching identical gains for the worse-off with equal or greater gains for the better-off, there is no reason to favour the former over the latter. Frankfurt's sufficiency position thus justifies being concerned about poverty, but distinguishes it sharply from being concerned about inequality. While it must be noted that Frankfurt's target here is very narrow (he is focusing on discrepancies of income and wealth and is attacking strict egalitarianism) it nevertheless supports views which dismiss comparative perspectives that are at the core of inequality concerns, and, in this sense, also at the core of the notion of relative poverty. ${ }^{2}$

From a sufficiency perspective, we might be interested in reducing inequalities for instrumental reasons, where an empirical relation between poverty and inequality is established. Our concern with inequality would thus have a derivative moral significance and empirical evidence is of central importance in order to support this relationship.

Sufficiency views support the idea that poverty is the fundamental concern for social justice. There are, however, two further key normative positions that uniquely justify our concerns with poverty. Firstly, proponents of humanitarian views stress reasons for caring about poverty that put 'humanity 
before justice' (Campbell, 2007). According to these views, our core moral reason to care about poverty springs from the sheer horrible suffering that is associated with it. Campbell asserts that this concern is compatible but distinct from instrumental justifications (that see, for example, subsistence as a precondition for other human activities, which in turn one might value for moral or non-moral reasons). Ultimately, in this humanitarian perspective, poverty is an evil experienced by the poor and the core moral reason to care about it is the suffering "that lack of the means of subsistence causes: hunger, pain, misery, sickness, and death" (2007, p. 63). Humanitarian concern gives rise to a positive duty to help the poor. Along these lines, Singer (1972) has famously developed what is probably the most influential version of this humanitarian view in relation to global poverty.

This kind of view has some important consequences for our approach to poverty: on the one hand, in promoting desirable consequences for the poor, humanitarian aid is not sensitive to how a certain state of affairs came to be - our moral obligation holds, irrespective of who is suffering or why that suffering came about. Alleged moral failures of those in need also do not allow exculpatory rationales for those who can offer aid. On this view, poverty is "the basis of a universal, unqualified claim based on the moral relationships between those who suffer and those who can do something about it" (Campbell, 2007, p. 66). This position can lead to rather radical conclusions because it conceives of our duty to aid as demanded on all of us, as individuals, in accordance to our capacity and irrespective of proximity. In turn, this calls into question a focus on domestic poverty over global poverty (Singer, 1972, p. 232).

An in-depth discussion of humanitarian views and their critics cannot be fully explored here. However, it is worth pointing out that, aside from practical concerns with Singer's solution regarding humanitarian aid (Wenar, 2011), there are difficulties in defining the limits of beneficence as an obligation. It is because our duty of beneficence does not specify exactly how much assistance we must provide to others that Kant defined it an imperfect duty (G 4:421). This in turn can lead to claim that positive moral duties to charity are supererogatory and non-enforceable, pertaining to a moral 
ideal (Gert, 2005), rather than a moral obligation. Moreover, appealing to benevolent sentiments - to "the elemental response of aiding another human being arising from seeing, imagining, or knowing of the suffering" (Campbell, 2007, p. 65) - is not unproblematic. ${ }^{3}$ On the one hand, the variance of feelings of empathy from person to person leaves undefined the suffering we are morally obliged to alleviate. On the other hand, while it might be that the extreme experiences discussed by these authors in the context of global poverty elicit this "elemental response of aiding", these intuitions are not always clear. For example, in some cases, but not in others, painful experiences of the poor (e.g. shame, stress, fear of the future, absence of control over one's destiny, as well as degrading working conditions etc. $)^{4}$ seem to be balanced against judgements about their responsibility, for instance in relation to domestic or relative poverty. Appeals to humanitarian concerns are thus not as simple as it would prima facie appear and clarifying the concept of poverty underlying these approaches is crucial for policy making, as it bears not only on measurement but on the actors involved and the strategies developed.

A second justification that emerges in relation to poverty sees it as constituting a violation of the human rights of the poor. Rights-based justifications have gained considerable prominence in the context of philosophical discussion of global poverty. Where poverty is considered as a violation of human rights (Pogge, 2007; Gewirth, 1983; Ashford 2007; Cruft, Liao \& Renzo, 2015) freedom from poverty is taken to be a right humans have simply in virtue of being human, hence constitutive to realizing valued features of human life. This can be understood in three ways: 1) as respecting human dignity (Griffin, 2008), especially in connection with agency and autonomy; 2) as promoting fundamental human interests (Tasioulas, 2007, 2015; Ashford 2007) and hence a good life; 3) as protecting the opportunity to meet human needs (Miller, 2012), the conditions for a minimally decent life (these are needs all human beings have qua human beings and are not dependent on any specific goal). 
A stance, prominently developed by Thomas Pogge (2002, 2007), sees our decisions regarding what we should do about global poverty as concerning the reasons why there is persistent poverty in the face of material abundance (Gomberg, 2002). Pogge sees causality as having a particular moral significance, making poverty a violation of human rights. According to him, "severe poverty today, while no less horrific than that experienced by the early American settlers, is fundamentally different in context and causation. Its persistence is not forced on us by natural contingencies of soil, seeds, or climate. Rather, its persistence is driven by the ways that economic interactions are structured" (Pogge, 2007, p. 3). Instead of solely focusing on the consequences, such as the suffering experienced by the poor, this view turns to the nature of the relations that brought these consequences about. Poverty is not simply a fact in the world, but instead, it is a foreseeable and avoidable harm, which sees institutions violating human rights through their policies, even if creating poverty was not the explicit aim of policy. This makes Pogge's view radically different from ones focused on humanitarian aid and stresses a strong negative duty not to harm the poor by imposing a political, economic and social order that systematically sustains poverty. ${ }^{5}$ Critics of Pogge's approach point out that it is limited to the kind of impoverishment that other agents are causally and morally responsible for, while it also hinges on establishing complex causality in regards to poverty which is, in the literature, both elusive and controversial (Risse, 2005; Cohen, 2010; Vizard, 2006).

More generally, rights-based approaches offer strong justifications for policies earmarked to eliminate poverty. At the same time, especially since they focus on subsistence rights and have been developed in relation to extreme poverty, understood predominantly in absolute terms, they might be less relevant for relative and domestic poverty. Moreover, it might seem that such views do not in turn justify concerns with inequality (Gewirth, 1996, pp.72-73, 110). These perspectives, however, can be compatible with instrumental reasons for caring about inequalities: for example, by noting that the persistence of poverty is self-reinforcing and entrenched in a context of great inequality (Pogge, 2007, p. 4). 


\section{How reasons for caring about poverty and inequality overlap}

In the last two sections, we have explored how different normative positions ascribe priority to either inequality or poverty. In this section, I will discuss how it is possible to support a pluralist approach that sees our reasons for caring about these as compatible. A first issue that deserves attention is the particular way in which the broader understandings of both poverty and inequality have been developed in response to limitations ascribed to narrow approaches to these concepts.

In fact, one of the developments of the discussion surrounding the "currency of equality", briefly mentioned above, has been the broader focus on social inequalities. These views oppose the Rawlsian emphasis on resourcism, which focuses predominantly on distributional inequalities (Sen, 1980; Robeyns \& Brighouse, 2010). Developing these insights, conceptions of social or democratic equality (Anderson, 1999; Wolff, 2015) have stressed that we should be concerned with patterns of socialization, defining social relations, rather than merely patterns of distribution. According to these views, inequality is conceived as a fundamentally relational notion. They do not dismiss the importance of inequalities of wealth and income and hold that certain patterns of distributions are inextricably connected to relationships that fail to amount to those of a 'society of equals'. This means that, on the one hand, distributional features of society are important determinants of social inequalities, which consist of asymmetrical relationships of political power, or status, but also of exclusion and discrimination. On the other hand, overcoming distributional inequalities is not sufficient to achieve social equality because, for example, certain forms of exclusion can be rooted in reasons other than the possession of material resources (such as gender, race or disability). In this sense, we can see a more explicit attention to forms of horizontal inequality. ${ }^{6}$ This also means that, in these relational models of equality, the relevance of distributional inequalities is relative to the extent to which they can result in social inequalities, for example by being converted in social status 
and political power. In this direction, Nancy Fraser $(1998,2007)$ has proposed a broad conception of social justice as "parity of participation": in order for this to be achieved, economic redistribution, social recognition, and political representation should not be considered antithetical and mutually exclusive, but seen as rather defining different, entwined, and reciprocally reinforcing dimensions of justice.

Similarly, sufficiency views have been pressed with answering the question: 'enough of what'? Answers can be articulated in various forms: for example, in terms of resources, welfare or capabilities. Capability approaches (Sen, 1980, 1999; Nussbaum, 1988, 2000) have been particularly prominent in the discourse surrounding the analysis of poverty (Hick, 2012) and allow us to develop an understanding of poverty that is broader than material resources. Capability approaches are concerned with what is necessary for human functioning: what matters is not what you possess, or how happy or satisfied you are, but what you are able to 'do or be'. From this perspective, poverty is viewed as the deprivation of certain basic capabilities, and these can vary, as Sen has argued, 'from such elementary physical ones as being well nourished, being adequately clothed and sheltered, avoiding preventable morbidity, and so forth, to more complex social achievements such as taking part in the life of the community, being able to appear in public without shame, and so on' (Sen, 1995, p. 15). As a result, capability approaches acknowledge the multidimensional nature of poverty, with a broader scope than focusing solely on 'material' poverty. Debates originated from capability approaches allow us to consider the limits of the ordinary focus on the lack of material resources for explaining all deprivation: because of this, we cannot assume that relieving poverty will be enough to eliminate deprivation. Even if we maintain a definition of poverty that is closer to the ordinary understanding, as material deprivation, we can see that the reason that we should be especially concerned with poverty derives from its being the most important cause of deprivation understood more broadly. 
There is an interesting parallel to draw here with the considerations about social equality we just explored: there, we saw that the ability to participate in the life of society is not just constrained by disparity and lack of resources. Here, we find a normative inseparability of the concepts of poverty and deprivation understood more broadly, in the same way in which we saw distributional inequalities being constitutive, but not exhaustive, of the concept of social inequality. At the same time, we can also trace a parallel normative concern that underlies these approaches and pushes us to understand the relationships between poverty and inequality within an overarching concern with deprivation. Even if one was to ascribe priority to making the poor escape poverty, especially extreme poverty, over tackling distribution gaps (as we have seen is the case for rights-based or humanitarian approaches), this "need not commit us to the very different assertion that this is all that justice requires" (De Vita, 2007, p. 108). ${ }^{7}$ Fleurbaey, for example, sees poverty and inequality inextricably connected to forms of oppression that represent, though in different degrees, a violation of human integrity and dignity. Where the wrong of poverty is associated with the oppressive nature of the relationship between rich and poor, we find our normative concerns with poverty and inequality to be inextricably linked. In fact, in this view, inequalities of wealth are constitutive of the distortion in economic, social, and political relationships. Our normative concerns about inequality and poverty both originate and are justified by the core commitment to respecting human integrity and dignity, which makes them both instances of violations of justice.

More generally, there are both intrinsic and instrumental reasons why, even in a rights-based view primarily concerned with poverty, inequality of resources above the minimal threshold does matter, morally speaking, from the standpoint of justice. Inequalities of wealth and income matter because they are associated with inequalities of social status that produce humiliation and undermine selfrespect; but also because they are converted in imbalances of political power that undermine the political liberties of the least privileged (De Vita, 2007, p. 109). Whether one starts from a concern 
with poverty, or starts with a concern about inequality, tackling both matters to respect and promote human dignity.

With this in mind, we can see that when we claim that it is possible to hold a pluralist approach, we conceive it as building connections among these different reasons (instrumental and intrinsic, moral and non-moral) rather than considering them mutually exclusive. The capability approach seems to allow such a view. ${ }^{8}$ We have seen how capability approaches are concerned with ensuring people's capabilities to function in ways that are elemental to human life. Material deprivation is probably the most important barrier to this goal, while material inequalities can be seen as important determinants of unequal treatment and discrimination, which are constitutive of deprivation, broadly understood. So, from a capability approach perspective, these aspects of social equality are also necessary for one's capability to function. At the same time, instrumentally, income redistribution is likely needed to meet the thresholds set by the capability approaches. Poverty, as lack of material resources, and inequalities, material as well as relational, all raise normative concerns because they are barriers to people's capabilities to function in ways that are elemental to human life.

\section{The implications of taking a pluralist approach}

To sum up our discussion so far, we have seen how different philosophical theories provide different reasons why we should care about poverty and inequality. For some authors these appear to be in conflict, inviting us to prioritise one issue over the other. These different theories also lead us to focus on different aspects of inequality (e.g. one can focus solely on differences of wealth and income, or on the inequalities that characterise social relationships) and on different aspects of poverty (one can focus on global poverty over domestic poverty; or focus on absolute rather than relative poverty; or care about how the poor came to be in this position or not). Nevertheless, this paper suggests that it is possible to argue that our concerns with poverty and inequality are not 
mutually exclusive. We can plausibly hold, for instance, that both poverty and inequality are relevant for human deprivation, or that they are both violating human dignity, or that they stand in mutually reinforcing relationships and hinder other social goals.

Adopting a pluralist approach that does not juxtapose normative concerns about poverty and inequality has consequences for both conceptual and practical debates. For instance, it offers a normative ground for a research and policy agenda focused on the connections and the dynamics between these phenomena. It would encourage, for example, the growing focus of empirical studies on social exclusion (Forster \& Vleminck, 2004), which aims to identify affected groups and the processes by which exclusion occurs, examining these in correlation with various dimensions of deprivation. By way of conclusion, I will suggest two directions in which this work could be further developed: one that invites us to focus on the relationship between this debate and connected issues pertaining to the attribution of responsibility, in relation to both poverty and inequality. A second direction for further research sketched here will suggest how the normative considerations presented can be used in relation to the current debate around "inclusive growth".

\subsection{Questions of Responsibility}

Issues of responsibility are central to much of the public debate surrounding measures and policies targeted to inequality and poverty. Policy discourses about poverty and inequality differ according to the extent to which responsibility is attributed to individuals and families, or to institutions and economic structures. Some of the normative positions examined in this paper could justify the claim that there is a fundamental asymmetry between poverty and inequality when it comes to responsibility. For instance, from a humanitarian perspective, issues of responsibility are irrelevant in relation to poverty. However, if we adopt a view that sees our normative concerns about poverty and inequality overlap, we can tackle issues regarding responsibility by exploring the parallels that emerge in 
relation to these phenomena. Generally, we can see how the issue of responsibility arises from the fact that inequality and poverty are distinctively human and social phenomena. As such, they bring to the forefront questions regarding agency in a way that natural phenomena do not. ${ }^{9}$

For instance, the idea that there is a significant difference between those who are poor or worse-off through no fault of their own and those who are responsible for their condition has particular resonance both in philosophy and policy. Research in social policy has focused on how beliefs about personal responsibility play a substantial part in shaping people's preferences, for instance in regards to redistribution or policies targeting poverty (Alesina \& Glaeser, 2004; Smeeding \& Osberg, 2006). Public attitudes that understand poverty and disadvantage in terms of individual failures legitimise them as fair and influence policy-making, constraining the capacity of governments to develop strategies accordingly (Toth, Horn \& Medgvesi, 2014).

In philosophy, luck egalitarianism seems to propose an understanding of fairness which supports the idea that we do not have duties of justice towards those who can be held rightfully responsible for their situation (Dworkin, 1981; Arneson, 1989; Cohen, 1989). This means that a desert principle defines the very notion of fairness, and hence it bears directly on the forms of inequality equity justifies. Individuals' active role in the production of goods is thus a key factor determining the ground of institutional intervention as individual choices are seen as bearing on social justice claims. Importantly, Dworkin's luck egalitarianism is offered as an ideal theory and hence it assumes fair background conditions to be in place before ascribing full responsibility.

While luck egalitarianism proposes an understanding of fairness which is in line with prevailing intuitions in society (Wolf et al, 2015), this view contrasts sharply with Rawls's own dismissal of desert considerations: he holds that these could not have any role in distributive justice, since undeserved factors have a major influence on all would-be desert bases (Sher 1987, p. 22). Indeed, 
how to draw the distinction between freely made choice and bad luck has attracted much debate (Arneson, 1989; Cohen, 1989), and it might be particularly difficult to apply luck egalitarian principles in practice (Wolff et al, 2015). Moreover, in practice, instrumental reasons (e.g. in relation to efficiency or social cohesion) might prescribe to reduce certain inequalities even where these would be of no concern from a luck egalitarian perspective. However, the principles underpinning luck egalitarian fairness have received cross-disciplinary attention and are at the foundation of a substantial growing body of economics literature centred around the notion of equality of opportunity (Barros et al. 2009; Brunori et al. 2013; Fleurbaey \& Peragine 2009). This research seeks to operationalise the notion of equality of opportunity, distinguishing it from income inequality and inequality of outcome more generally. On the one hand, this shift of focus hopes to facilitate political and policy consensus; on the other, while recognising cross-country variations and the importance of understanding specific contextual challenges (Barros et al. 2009), this empirical evidence has made important steps in investigating the relation between inequalities of income and opportunities. For instance, Brunori et al. (2013) suggest that an important portion of income inequality cannot be attributed to differences in individual efforts or responsibility, and see inequalities in income and opportunities as both endogenously determined (p. 13).This empirical work can add to the debate surrounding inequality and responsibility, problematizing the notion of choice: for a theory of equality of opportunity to become operationally or empirically meaningful, one must decide which factors should be classified as circumstances beyond the control of the individual, and which should be counted as choices for which individuals are to be held responsible. This calls for a robust understanding distinguishing between a direct effect of circumstances on outcomes and an indirect effect via choice or effort.

Challenges surrounding agency and the notion of choice also emerge in relation to poverty. Where some see the behaviour of those in poverty to be a key factor of the persistence of poverty (Karelis, 2007), a consistent portion of the philosophical discussion surrounding poverty points at its effects 
on agency. Where poverty is seen as reducing real freedom, some choices are choices only in appearance (Fleurbaey, 2007). So, for example, Christman (1998) questions a common misconception about the incentives structure of the poor that sees labour as constituting a disutility for them. He argues that such claims are based on a misunderstanding that makes "independence" rather than "autonomy" a goal of social policy, and that when we acknowledge the value and the place of interdependency in our lives, we cannot consider 'dependence' as an evil to eliminate, but we should rather see "autonomy" as a basic value when discussing welfare programs. Autonomy, unlike "independence", is not committed to the deceivingly neutral assumption of a life of wage labour and paid employment as the norm; moreover, Christman argues, autonomy is essential for both democracy and markets because they both require the choices of participants to be made from a condition which truly reflects an authentic, non-distorted appraisal of their interests. Since the incentive structure of welfare to work programs is such that employment decisions are taken from a position of deprivation and diminished autonomy, the resultant choices/outcomes will likely be ones from which the person will be, upon critical reflection, deeply alienated. Programs that induce market entrance without securing autonomy conditions are, in a sense, self-defeating.

These common challenges, in regards to the notion of choice and the relationship between autonomy and independence, are central to agency and as such connected to the concept of human dignity. On the one hand, not all choices are equally free and it is particularly difficult to ascribe responsibilities for choices made under complex circumstances, especially for those who are socially excluded or at risk of poverty. On the other, it would seem demeaning to say that those in poverty are never responsible for the consequences of their choices (Wolff \& de-Shalit, 2007).

Responsibility is discussed not just in relation to individuals, but also in terms of our collective responsibility for structures and institutions. In the first section we saw Rawls presenting the difference principle, concerning distributional inequality, as a principle of justice, which he conceived 
as "the first virtue of social institutions" (1971, p. 3). At the same time, structural responsibility is particularly central for rights-based views: the legitimacy of institutions is seen as dependent on their fairness and on their ability to respect moral rights, including welfare rights and these moral rights ground institutions, which are meant to protect them and translate them into legal rights. If we are to understand the role responsibility plays in shaping our concerns with poverty and inequality, issues of causation seemingly need to take the forefront. At the same time, it is important to point to philosophical debates that surround the very notion of responsibility: for example, the work of Iris Marion Young (2003) invites us to question a "liability" conception of responsibility (causally connecting agents to harms), and she stresses how this fails to understand structural injustice which, while it is socially caused, does not result from the action of few specifiable actors. According to Young, we need to acknowledge the shortcomings of this dominant conception of responsibility, because it is inadequate for evaluating the relationships between individual actors and large-scale social processes and systemic injustices.

To sum up, questions of responsibility emerge both in relation to poverty and inequality and complicate the picture. On the one hand, the very fact that these are distinctively human phenomena brings to the forefront issues of agency in a way natural phenomena do not. On the other, at both the individual and structural level, we find parallel problems in establishing how certain states of affair came to be and how a meaningful notion of responsibility should be defined. While the discourse of responsibility and desert is prominent in the way our society approaches poverty and inequality, these considerations invite us to take into account the limits of our intuitions, and require us to focus on the causes and processes underlying poverty and inequality.

\subsection{Inclusive Growth}


A second consideration refers to the way in which these normative insights can be applied to current policy debates. A growing body of research and initiatives have focused on 'inclusive growth' (IMF, 2017; OECD, 2017; Green et al 2017). In fact, reversing longstanding assumptions, inequality has been shown to have negative effects on growth (Ostry et al, 2014; Bénabou, 1996), leading to weaker economic performance, negatively affecting medium-term growth and tending to shorten growth spells (Cingano, 2014). Growth is more durable in societies with greater equality: this implies that the analysis of growth and inclusion cannot be decoupled (Berg \& Ostry, 2011). The GINI research project, funded by the European Commission and involving 30 countries, has examined the growth of inequality in a thirty-year period and stressed the important role played by policy, with reduced redistribution and government retrenchment as key drivers for growing inequality since the $80 \mathrm{~s}$ in many countries (Salvareda, 2014; Hacker \& Pierson, 2010). At the same time, in some countries, such as the UK, more people now live in poverty who are in working, rather than workless, households (Tinson et al, 2016). Patterns of inequality and poverty are rooted in longstanding structural problems (e.g. the decline of traditional industries and the shift from a manufacturing to a service economy) and require researchers and policymakers to reconsider arrangements - from the structure of the labour market to the provision of public services - that involve the whole of civil society, all levels of the public sector, as well as employers. 'Inclusive growth' is understood as "broad sharing of the benefits of, and the opportunities for, economic growth, and reflects growth that is robust and broad-based across sectors" (IMF, 2017, p. 5). From the development of instruments to monitor inclusion (Kireyev and Chen, 2017) to more local-based programmes (IGAU, 2016; Green et al 2017), inclusive growth is developed in different regions as setting an agenda on how the economy and the state can be restructured to ensure that the benefits of economic prosperity are shared.

The idea of "inclusion" that is central to this agenda, as developed by different actors and in different settings, remains, however, ambiguous in regards to the normative commitments underpinning it. 
These are important, as they implicitly define the goals of this agenda and therefore affect the criteria of success shared by these initiatives.

The mechanisms linking inequality, poverty and growth can be understood as central to an agenda that focuses on economic outcomes. Economic exclusion has been shown to have great human and economic costs, which affect not just the most disadvantaged segments of the population but society as a whole, with lower spending, human capital, productivity, and additional pressures on public spending. In this sense, inclusion and consideration for poverty and inequality can be fundamentally instrumental for a growth that is embedded in the existing economic model. As we have explored above, these instrumental considerations make the normative concern with poverty and inequality contingent. On the other hand, normative commitments that centre around poverty and inequality have more radical consequences, and ultimately reconceive growth as inherently linked to the promotion of these social goals. In this sense, it is not simply that more growth requires more inclusion, but rather that growth entails a commitment to promoting and respecting human dignity and integrity, and hence a model of economic prosperity that changes to achieve greater inclusion. This means, for example, that a focus on the quality of employment does not merely reflect concern with sustainability and with the costs of current arrangements for the economy, but actually sees employment as the basis for people to feel included in society and have a sense of dignity (Loungani, 2017). In practice, the difference between these approaches can also bear on their support for strategies that promote different forms of economic growth which might be slower growing or require long-term change - for instance some that aim at expanding social networks, e.g. through the development of different forms of business such as co-ops or social enterprises, or reconsider the nature of industrial relations and the financial system (IGAU, 2016; Green et al, 2017). A coherent engagement with the normative tenets of approaches to inclusive growth would likely affect the forms of inequality and the dimensions of deprivation and disadvantage that are considered relevant for the 
inclusive growth agenda. As we have seen, our normative concerns are intimately connected to our understanding of both inequality and poverty.

What emerged from our analysis is the possibility of endorsing a broader social justice justification for which inequality and poverty do not generate competing concerns, but instead see overlap in our normative reasons to care about both. A conception of social justice that focuses on patterns of socialization and not solely on patterns of distribution does not deny the importance of material inequalities: these are considered a key determinant of broader social inequalities, inextricably linked to their reinforcement. Capability approaches, as well as theories focused on social and relational inequality, seem to point in this direction. These approaches do not try to define the grounds of justice (its principles as well as necessary and sufficient conditions). Instead, their point of departure is the broad real world social justice concern with social inequalities and deprivation. From the standpoint of a broader conception of social justice, we find that poverty and inequality are constitutive of human deprivation. This allows normative philosophical analysis to bring to the forefront their mutually reinforcing relationships, while supporting and clarifying policy debates.

\section{Notes}

1. I cannot do justice here to the array of utilitarian positions that have elaborated on these themes. Given the centrality of the utilitarian influence in economic debates, I pointed at the inherent difficulties in resolving tensions between utility and justice. For further discussion of possible utilitarian solutions and rule utilitarianism see Hooker (2014).

2. Relative poverty is conceived as a level of deprivation that changes in line with changes in the general living standard (e.g. by considering poor to be those whose household income, adjusted for family size, falls under a certain agreed threshold of a country's median income). This is one of the agreed international measures used throughout the European Union. Instead, the concept of absolute poverty refers to a level of deprivation that does not change as the general living standard changes over time and is often associated with acute deprivation.

3. A long-standing discussion which cannot be explored here revolves around the extent to which our feelings can ground normativity and provide the basis justifying our concern (Korsgaard, 1996). According to this Kantian objection, "[m]oral feeling succeeds the moral concept, but does not produce it" (Kant, NF 19:150, 6757).

4. There is a vast literature on this topic. See Fleurbaey, 2007; Creegan et al., 2009; Taylor-Gooby, 2013; Walker 2014.

5. One of the strengths of Pogge's position is that it supports the urgency of acting against poverty even for those who only recognize the stringency of negative duties. There is, however, also substantial 
support to the idea that a human right to basic necessities imposes both negative and positive duties (Sen, 1982; Cruft, 2005; Ashford 2007, Shue, 1996). A large part of the philosophical discussion around rights-based approaches has concerned this identification of positive and negative duties, a topic which cannot be fully explored here (O’Neill, 1996; Shue, 1996; Geuss, 2001).

6. Vertical inequality refers to inequality in material resources as measured between all individuals or households in a distribution, while horizontal inequality is defined as inequality between groups, typically population subgroups defined by cultural characteristics - e.g. by ethnicity, religion or race (Stewart, Brown and Cobham, 2009). Rawls's difference principle fundamentally concerns vertical inequality. Criticisms developed by authors holding a relational view of equality point at the limits of resourcism emphasizing the cogency of concerns with horizontal inequalities. It is important to stress that underlying commitments of the philosophical literature to either horizontal or vertical inequality can be extrapolated, but they are, for the most part, not directly addressed. Disentangling the general unclarity surrounding these notions in the philosophical literature would be of particular interest in order to engage and contribute to the ongoing debate in social policy. This is, however, beyond the scope of this contribution.

7. For how these arguments apply both at the domestic and international level see Beitz 2001, De Vita 2007.

8. Notably, capability approaches are compatible with different principles of distribution (from strict egalitarianism to the Rawlsian difference principle). Nussbaum has developed a list of core capabilities which offers universal standards to set a social minimum that is 'worthy of the dignity of the human being' and endorses a 'sufficiency view' of capabilities (Nussbaum, 2000, p. 5). At the same time, the multidimensional analysis offered by capability approaches underpins attempts to conceptualise and measure poverty and inequality which are closely related to the claims explored here. For instance, the Equality Measurement Framework (Burchardt and Vizard, 2011) as well as Oxfam's Inequality Framework (McKnight and Prats, forthcoming) represent multi-dimensional approaches that monitor inequalities in the position of individuals and groups in terms of their substantive freedoms.

9. This is not to say, for example, that poverty does not also result from natural disaster or natural conditions, but as Lotter (2011) notices, zoo animals might suffer from cruelty or neglect but not poverty. Wild animals starve but do not live in poverty. Poverty, thus, seems to be related in some way to humanity.

\section{References}

Alesina, A. \& Glaeser, E. (2004). Fighting Poverty in the US and Europe: A World of Difference. Oxford: Oxford University Press.

Anderson, E. (1999). What is the Point of Equality?. Ethics, 109: 287-337.

Arneson, R. (1989). Equality and equal opportunity for welfare, Philosophical Studies, 56, 77-93.

Ashford, E. (2007). The Duties Imposed by the Human Right to Basic Necessities. In T. Pogge (Ed.), Freedom From Poverty as A Human Right (pp.183-218). New York: Oxford University Press.

Beitz, C. (2001). Rawls's Law of Peoples. Ethics, 110(4), 669-96.

Bénabou, R. (1996). Inequality and growth. In B. Bernake \& J. Rotemberg (Eds.) NBER Macroeconomic Annual (pp. 11-74). Cambridge, MA: MIT Press. 
Berg, A., \& Ostry, J.D. (2011). Inequality and Unsustainable Growth: Two Sides of the Same Coin?, IMF Staff Discussion Note 11/08, Washington: International Monetary Fund. Retrieved March 25, 2018, from https://www.imf.org/external/pubs/ft/sdn/2011/sdn1108.pdf

Bridstall, N. (2007). Income distribution: effects on growth and development. CGD Working paper 188, Washington DC: CGD.

Brunori, P., Ferreira, F., \& Peragine, V. (2013). Inequality of Opportunity, Income Inequality and Economic Mobility: Some International Comparisons. Policy Research working paper; No. 6304. Washington DC: World Bank. Retrieved March 25, 2018 http://documents.worldbank.org/curated/en/864781468331737091/Inequality-ofopportunity-income-inequality-and-economic-mobility-some-international-comparisons

Burchardt, T. \& Vizard, P. (2011). 'Operationalizing' the Capability Approach as a Basis for Equality and Human Rights Monitoring in Twenty-first-century Britain, Journal of Human Development and Capabilities, 12(1), 91-119.

Campbell, T. (2007). Poverty as a Violation of Human Rights: Inhumanity or Injustice? In T, Pogge (Ed.), Freedom From Poverty as A Human Right (pp. 55-74). New York: Oxford University Press.

Christman, J. (1998). Autonomy, independence and poverty-related welfare policies. Public Affairs Quarterly, 12(4), 382-405.

Cingano, F. (2014). Trends in income inequality and its impact on economic growth. OECD Social, Employment and Migration Working Papers, No.163, OECD Publishing. http://dx.doi.org/10.1787/5jxrjncwxv6j-en

Cohen, G. A. (1989). On the Currency of Egalitarian Justice. Ethics, 99(4), 906-44.

Cohen, J. (2010). Philosophy, Social Science, Global Justice, In A. Jaggar (Ed.), Thomas Pogge and his critics, (pp. 18-44). Cambridge: Polity Press.

Creegan, C., Warrener, M. \& Kinsella, R. (2009). Living with social evils: further views from people in disadvantaged groups. In D. Utting (Ed.) Contemporary Social Evils (pp. 65-82). Bristol: Policy Press.

Cruft, R. (2005). Human Rights and Positive Duties. Ethics and International Affairs, 19, 29-37.

Cruft, S. Liao, M. \& Renzo, M. (2015). Philosophical Foundations of Human Rights: An Overview. In R. Cruft, M. Liao M. Renzo (Eds.) Philosophical Foundations of Human Rights (pp. 141 ). Oxford: Oxford University Press.

De Vita, A. (2007). Inequality and Poverty in Global Perspective. In T. Pogge (Ed.), Freedom From Poverty as A Human Right (pp. 103 - 132). New York: Oxford University Press.

Dworkin, R. (1981a). What is Equality? Part 1: Equality of Welfare. Philosophy \& Public Affairs, $10(2), 228-40$.

Dworkin, R. (1981b). What is Equality? Part 2: Equality of Resources. Philosophy \& Public Affairs, $10(3), 283-345$. 
Fleurbaey, M. (2007). Poverty as a Form of Oppression. In T. Pogge (Ed.), Freedom From Poverty as A Human Right (pp. 133-154). New York: Oxford University Press.

Forster, M. \& Vleminckx, K. (2004). International comparisons of income inequality and poverty: Findings from LIS. Socioeconomic Review, 2(2), 191-212.

Frankfurt, H. G. (1987). Equality as a Moral Ideal. Ethics, 98(1), 21-43.

Fraser, N. (1998). Social Justice in the Age of Identity Politics: Redistribution, Recognition and Participation. In G.B. Peterson, (Ed.) The Tanner Lectures on Human Values, Vol 19 (pp. 167). Salt Lake City: University of Utah Press.

Fraser, N. (2007). Reframing Justice in a Globalizing World. In J. Connolly, J.M. Leach, L. Walsh, (Eds.), Recognition in Politics Theory, Policy and Practice (pp. 16-36). Cambridge: Cambridge Scholars Publishing.

Gert, B. (2005). Morality. New York: Oxford University Press.

Geuss, R. (2001). History and Illusion in Politics. Cambridge: Cambridge University Press.

Gewirth, A. (1983). Human Rights: Essays on Justification and Applications. Chicago: Chicago University Press.

Gomberg, P. (2002). The Fallacy of Philanthropy. Canadian Journal of Philosophy, 32 (1), 29-66.

Green, A., Froy, F., Kispeter, E. \& Sissons, P. (2017). How international cities lead inclusive growth agenda? Joseph Rowntree Foundation Report. Retrieved March 25, 2018 from https://www.jrf.org.uk/report/how-do-cities-lead-inclusive-growth-agenda

Griffin, J. (2008). On Human Rights. Oxford University Press.

Hacker, J.S. \& Pierson, P., (2010). Winner-Take-All Politics: Public Policy, Political Organization, and the Precipitous Rise of Top Incomes in the United States. Politics \& Society, 38(2) 152204.

Hick, R. (2012). The capability approach: insights for a new poverty focus. Journal of social policy, 41(2), 291-308.

International Monetary Fund (2017). Fostering Inclusive Growth, Notes prepared for G-20 Leaders Summit. Retrieved March 25, 2018 from https://www.imf.org/external/np/g20/pdf/2017/062617.pdf

Inclusive Growth Analysis Unit (2016). Towards Inclusive Growth in Greater Manchester: Summary Report. Retrieved March 25, 2018 from http://hummedia.manchester.ac.uk/institutes/mui/igau/Inclusive-Growth-SummaryReport.pdf

Karelis, C. (2007). The Persistence of Poverty. New Haven and London: Yale University Press. 
Kireyev, A. \& Chen, J. (2017). Inclusive Growth Framework. IMF Working Paper. Retrieved March 25, 2018 from

fhttps://www.imf.org/en/Publications/WP/Issues/2017/05/30/Inclusive-Growth-Framework44951

Korsgaard, C. (1996). The Sources of Normativity. Cambridge: Cambridge University Press.

Lotter, H. P. (2011). Poverty, Ethics and Justice. Cardiff: University of Wales Press.

Loungani P. (2017). The Power of Two: Inclusive Growth and the IMF, Intereconomics, 52(2), pp. 92-99.

McKnight, A. \& Prats, A. (forthcoming). Inequality Framework and Toolkit, Oxfam Consultation Report.

Miller, D. (2012). Grounding human rights. Critical Review of International Social and Political Philosophy, 15(4), 407-427.

Nussbaum, M. (1988). Nature, Functioning and Capability: Aristotle on Political Distribution. Oxford Studies in Ancient Philosophy, 6, 145-84.

Nussbaum, M. (2000). Women and human development: The capabilities approach. Cambridge: Cambridge University Press.

OECD (2017). Time to Act: Making Inclusive Growth Happen. OECD Policy Brief. Retrieved March 25, 2018 from http://www.oecd.org/inclusive-growth/Policy_Brief_Time_to_Act.pdf

O’Neill, O. (1996). Towards Justice and Virtue: A Constructive Account of Practical Reasoning. Cambridge: Cambridge University Press.

Osberg, L. \& Smeeding, T. (2006). 'Fair' Inequality? Attitudes toward Pay Differentials: The United States in Comparative Perspective. American Sociological Review, 71(3), 450-473.

Ostry, J., Berg, A., \& Tsangarides, C. (2014). Redistribution, Inequality, and Growth. Staff Discussion Note 14/02. International Monetary Fund.

Parfit, D. (1998). Equality and Priority. In A. Mason (Ed.) Ideals of Equality, (pp. 1-20). Oxford: Blackwell.

Pickett, K. \& Wilkinson, R. (2009). The Spirit Level: Why equality is better for everyone. London: Bloomsbury press.

Pigou, A.C. (1920). The Economics of Welfare. London: Macmillan.

Pogge, T. (2007). Severe Poverty as a Human Rights Violation. In T. Pogge (Ed.), Freedom From Poverty as A Human Right (pp. 11-54). New York: Oxford University Press.

Rawls, J. (1971). A Theory of Justice. Cambridge, MA: Harvard University Press.

Rawls, J. (1999). The Law of People. Cambridge, MA: Harvard University Press. 
Risse, M. (2005). How Does the Global Order Harm the Poor?. Philosophy and Public Affairs, $33(1), 349-376$.

Robeyns, I. \& Brighouse, H. (2010). Introduction: Social primary goods and capabilities as metrics of justice. In H. Brighouse and I. Robeyns (Eds.) Measuring Justice: Primary Goods and Capabilities (pp. 1-13). Cambridge: Cambridge University Press.

Salvareda, W., Nolan, B., Checchi, D., Marx, I., McKnight, A., Tóth, I. G., \& van de Werfhorst, H. (2014). Introduction. In Changing inequalities in rich countries: analytical and comparative perspectives (pp. 1-14). Oxford: Oxford University Press.

Sen, A. (1980). Equality of What?. In S. McMurrin (Ed.), The Tanner Lectures on Human Values (pp. 196-220). Salt Lake City: University of Utah Press and Cambridge University Press.

Sen, A. (1995). The political economy of targeting. In D. van de Walle and K. Nead. Public spending and the poor (pp. 11-24). Washington, DC: World Bank.

Sen, A. (1999). Development as Freedom. New York: Knopf.

Sher, G. (1987). Desert. Princeton: Princeton University Press.

Shue, H. (1996). Basic Rights: Subsistence, Affluence, and U.S. Foreign Policy. Princeton, NJ: Princeton University Press.

Solomon, M. (2011). Why should it matter that others have more? Poverty, inequality and the potential for human rights law. Review of International Studies, 37(5), 2137-2155.

Solt, F. (2008). Economic inequality and democratic political engagement. American Journal of Political Science, 52(1), 48-60.

Solt, F. (2010). Does economic inequality depress economic participation? Testing the Schattschneider Hypothesis. Political Behaviour, 32(2), 285-301.

Stewart, F. (2013). Approaches towards inequality and inequity: concepts, measures and policies, Office of Research Discussion Paper No. 2013-01, UNICEF Office of Research. Retrieved March 25, 2018, from https://www.unicef-

irc.org/publications/pdf/stewart\%20inequality_inequity_layout_fin.pdf

Stewart, F., Brown, G. \& Cobham, A. (2009). The Implications of Horizontal and Vertical Inequalities for Tax and Expenditure Policies, CRISE, Department of International Development, University of Oxford. Retrieved March 25, 2018, from https://ora.ox.ac.uk/objects/uuid:b29fbd79-383c-41d5-911c-627204b2bdfe

Stiglitz, J. (2015). Inequality and Growth. In M. Mazzucato and M. Jacobs (eds.), Rethinking Capitalism, The Political Quarterly, 86, 134-155.

Tasioulas, J. (2007). The Moral Reality of Human Rights. In T. Pogge (Ed.), Freedom From Poverty as A Human Right (pp. 75-102). New York: Oxford University Press.

Tasioulas, J. (2015). On the Foundations of Human Rights. In R. Cruft, M. Liao M. Renzo (Eds.) Philosophical Foundations of Human Rights (pp. 45-70). Oxford: Oxford University Press. 
Taylor-Gooby, P. (2013). Why Do People Stigmatise the Poor at a Time of Rapidly Increasing Inequality, and What Can Be Done About It?. The Political Quarterly, 84(1), 31-43.

Tinson, A., Ayrton, C., Barker, K., Barry Born, T., Aldridge, H. \& Kenway, P. (2016). Monitoring poverty and social exclusion 2016, Joseph Rowntree Foundation Report. Retrieved March 25, 2018, from https://www.jrf.org.uk/report/monitoring-poverty-and-social-exclusion-2016

Tóth, I.G., Horn, D. \& Medgyesi M., (2014). Rising inequalities: will electorates go for higher redistribution?. In W. Salvareda, B. Nolan, D. Checchi, I. Marx, A. McKnight, I.G. Tóth, \& $\mathrm{H}$. van de Werfhorst (Eds.) Changing inequalities in rich countries: analytical and comparative perspectives (pp. 195-217). Oxford: Oxford University Press.

Vizard, P. (2006). Pogge -vs- Sen on Global Poverty and Human Rights. Ethics and Economics, $3(2), 1-22$.

Walker, R. (2014). The Shame of Poverty. Oxford: Oxford University Press.

Wenar, L. (2011). Poverty is no pond: challenges for the affluent. In P. Illingworth, T. Pogge, L. Wenar (Eds.) Giving Well: The Ethics of Philanthropy (pp. 104 - 132). Oxford: Oxford University Press.

Wolff, J. (2015). Social Equality, Relative Poverty, and Marginalised Groups. In G. Hull (Ed.) The Equal Society (pp. 3 - 23). London: Lexington.

Wolff, J. \& de-Shalit, A. (2007). Disadvantage. Oxford: Oxford University Press.

Wolff, J. Lamb, E., \& Zur-Szpiro, E. (2015). A philosophical review of poverty, Joseph Rowntree Foundation. Retrieved March 25, 2018, from https://www.jrf.org.uk/report/philosophicalreview-poverty

Young, I. M., (2003). Political Responsibility and Structural Injustice. The Lindley Lecture, University of Kansas. 